Believing in hunters and gatherers

John E. Pfeiffer

Historical Atlas of World Mythology.

Vol.1, The Way of the Animal Powers.

By Joseph Campbell.

Alfred van der Marck Editions, San

Francisco (distributed by Harper \&

Row): 1984. Pp.304. \$75. To be

published in the UK on 30 June by

Times Books, $£ 35$.

MYTHS are taken more seriously nowadays than was the case two world wars and a holocaust ago, when the distinction between primitive and civilized cultures seemed more clear-cut. No longer viewed as tall tales, as the superstitions of tribal and pre-tribal peoples in faraway places, myths are appreciated as highly structured belief systems serving chiefly to hold societies together. For more than half a century these systems have been the overriding concern of Joseph Campbell, Professor Emeritus of Religion at Sarah Lawrence College in New York, with the past decade or so devoted to his major work: the compilation of a historical atlas of world mythology, which will appear in four volumes over the next two years.

Volume 1, The Way of the Animal Powers, deals with the origins of mythmaking during hunter-gatherer times. It is far more than an atlas, if that implies a book consisting predominantly of maps. There are indeed plenty of maps, 50 to be precise, but they supplement an extensive text which makes up the bulk of the book and in which Campbell confronts the most formidable question of cultural evolution - of what possible value could myth be to the human animal, a minority species engaged to the hilt in competition with other predators for food and living space? After all, our ancestors endured for ages and managed to increase their numbers appreciably without the benefit of myth, at least as far as we can tell from the archaeological record.

Hominids, members of the human family, arose in Africa five or more million years ago, stayed there for at least three to four million years, and then spread to Europe and Asia and, most recently, to Australia and the New World. This process is illustrated in a series of informative maps, which also indicate glacial advances and retreats as well as progressive stages in the art of tool-making. The first signs of myth, the first hints that the human species was off on a new tack, date back 50,000 to 100,000 years, only yesterday on the evolutionary time scale. The notion that death is a beginning not an ending, that we live on invisibly in an afterlife, has been traced to the earliest known burials in western Europe, Neanderthals laid to rest on their sides as if asleep, and with mint-condition tools and provisions for their journeys to another world.

An explosion of myth, what Campbell calls "the awakening of awe", came not long afterwards with the passing of the Neanderthals and the emergence of our kind of hominid, euphemistically known as doubly wise Homo sapiens sapiens. sharper focus in organizing his book. All the basic findings and ideas are there, but so dispersed that their net impact is somewhat weakened. On the other hand, he has produced an outstanding survey of huntergatherer beliefs, and a much-needed reference work. We can look forward to his forthcoming volumes on the nature of

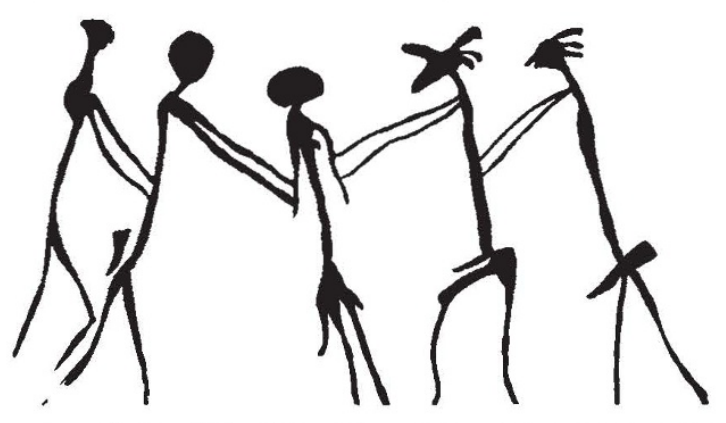

Ceremony appeared as a major feature of prehistoric life, increasingly elaborate performances staged deep underground in the limestone caves of western Europe. Only the art remains, the backdrops - vestige figures representing the world's first "art movement" which culminated 20,000 to 10,000 years ago with superb animals, bison and mammoths and other big game, painted and engraved on cave walls. It is as if all we had from the times of Gothic cathedrals were stained-glass windows and graven gargoyle images.

According to Campbell, no single cause can explain the spectacular rise of myth. For one thing, there was crowding, individual against individual, with soaring population densities, and myth was embodied in ceremonies designed to create closer tribal ties. The related need to feed more people, to kill magnificent animals on a mass basis, resulted in an additional conflict of conscience "with a compensatory mythology ... of a bonding covenant between the animal and human communities". Further factors contributing to "the creative explosion", included the landscape itself with its deep caverns "inspiring religious awe", the arrival of modern human beings, and the "visionary trance-seizures" of shamans who tapped unconscious forces in devising healing rites and initiations.

Campbell marshals ethnography as well as archaeology to support his analyses. $\mathrm{He}$ covers the world in describing the living folklore of present-day and recent huntergatherers, including the desert-dwelling Australian aborigines and Kalahari Bushmen, Eskimos, Tierra del Fuegians and Andamanese Islanders, forest peoples such as the Zaire pygmies and the recently discovered Tasaday of the Philippines all complete with maps presenting geographical distributions of art styles and cults, and a unique index of myth motifs from "Aardvarks" to "Yucca fruits".

I only wish that in the process of bringing all of this information together, a prodigious task, Campbell had achieved a
Art of African hunter-gatherers, possibly depicting the ritual abduction of a girl (by animalheaded figures on the right, resisted by the figures on the left). The illustration is taken from A. R. Willcox's The Rock Art of Africa, a scholarly and well-illustrated book recently published by Croom Helm in Britain and Holmes \& Meier in the United States. Prices are $£ 45$ and $\$ 69.50$, respectively. myths associated with agricultural societies, on the first civilizations, and on our own uncertain and increasingly complicated times.

John Pfeiffer's most recent book is The Creative Explosion: An Enquiry into the Origins of Art and Religion (Harper \& Row, 1982). He is currently completing a fourth edition of his textbook, The Emergence of Man.

\section{Nature of idealism}

\section{W.F. Bynum}

\section{The Philosophical Naturalists: Themes}

in Early Nineteenth-Century

British Biology.

By Philip F. Rehbock.

University of Wisconsin Press: 1983.

Pp.281. \$30, £25.50.

UNTIL a decade or so ago, historians of science seemed often to assume that the view of nature which Darwin's Origin of Species challenged was deeply rooted in a lingering, cautious Paleyite emphasis on special creation, individual adaptation and the argument from design. Romantic biology and transcendental anatomy were looked upon as largely Continental concerns which at best only marginally influenced empirically-minded British naturalists.

More recently, however, research by scholars such as the late Dov Ospovat, Adrian Desmond and Janet Browne has demonstrated the inadequacy of that view. Far from being ignored, "philosophical biology"' (as it might be called) was actively pursued by a number of leading British zoologists, botanists and anatomists. From the $1820 \mathrm{~s}$, many of the major themes of Continental biology were assimilated into British natural history: a continuing preoccupation with the "chain of being" and with an underlying unity of plan in plants and animals; concern with biological types rather than individual species; a willingness 
to speculate; and an explicit philosophical idealism.

Philip Rehbock's The Philosophical Naturalists can now be added to this growing historical literature, and the first half of his book, on "the idealist approach to nature", of fers an excellent summary of the relationship between British and Continental biology in the second quarter of the nineteenth century. Rehbock is not the first to note that Edinburgh was the cradle of much philosophical biology in Britain. Robert Knox, Robert Edmond Grant, Richard Owen, Edward Forbes, John Goodsir: these and several other apostles of the "new" biology of the 1820s and 1830 s shared a common intellectual heritage in the Scottish capital. Rehbock focuses on Knox (the unfortunate surgeon and anatomy teacher who received the victims of Burke and Hare), using his original writings and translations as a vehicle for expounding the main features of British transcendentalism. Owen and Goodsir receive rather more cursory treatment.

The second half of the book deals more comprehensively with the curious and often obscure biogeographical work of Edward Forbes, the attractive and personable naturalist who died in his prime, before the implications of his speculative vision of nature could be fully worked out. Forbes's research on what he called "centres of creation", and their connection with presently observed plant and animal distribution, was much discussed in the 1840 s, although it also involved him in one minor and one major priority dispute with Charles Lyell and Hewett Watson respectively.

Rehbock is a reliable guide to his chosen themes, and his book amply exposes the impact of philosophical idealism on preDarwinian natural science in Britain. It is not, however, a comprehensive analysis of the subject. The author is good on the Edinburgh scene, but weak on the London flowering of transcendentalism during the 1840s, when Owen, Grant, J.H. Green and others were active at University College, the Royal College of Surgeons and other London institutions. There is little attempt to place his major figures into their social, political or professional contexts. Rehbock also fails to assess (or even to cite) much relevant secondary literature, suggesting that little has been done on the book since 1975, when the PhD thesis on which it is based was completed. Occasional slips such as Humphrey [sic] Davy and Alfred Russell [sic] Wallace also mar the text. Nevertheless, publication of The Philosophical Naturalists is to be welcomed as another contribution to the understanding of the complex biological scene which flourished in Britain during the very decades in which Darwin was preparing his own statement.

W.F. Bynum is at the Wellcome Institute for the History of Medicine, London.
No stone unturned

Keith Bell

It Began with a Stone: A History of

Geology from the Stone Age to the

Age of Plate Tectonics.

By Henry Faul and Carol Faul.

Wiley: 1984. Pp.270. Hbk \$38.95, £35; pbk \$19.95, $f 16$.

CHARTING the development of geology from antiquity through to post-Wegenerian times is a formidable task. It Began with a Stone attempts to do just that. Packed with factual information, written in a breezy style and coupled to an extensive bibliography, it documents most of the highlights in the history of the earth sciences.

In this, the book is a success. Topics are numerous and diverse; not only is the classical age of geology covered in detail, but included are such lesser known subjects as the significance of French discoveries and theories in the seventeenth and eighteenth centuries, the establishment of the US State Surveys and even the fate of geologists during the American Civil War. Important developments in the earth sciences are nicely dovetailed into both a geographical and intellectual context.

The fragmented nature of geology started to disappear with the age of travel. Lyell's visit to eastern North America, his meeting with the cranky yet brilliant James Hall, Dana's and Wilkes's journey around the world, and the opening of the American West played important roles in the consolidation of new ideas and the provision of a solid basis for the relatively young science. This backdrop, together with a cast as intelligent, as colourful and as scurrilous as one could find, are among the fascinating material included in the Fauls' book.

It is difficult to compare this book with others of similar type. The Birth and Development of the Geological Sciences, published in 1938, although a more scholarly and sophisticated work, stops at the turn of this century and lacks the freshness and excitement of the Fauls' book. The style of delivery in the latter does, however, tend to be frenetic - a more relaxed pace would have helped readers absorb the bewildering array of information contained in the text.

The book can be read at two levels. For idle browsing, the many interesting and amusing asides can be savoured with relish. For more serious reading, the wealth of information provides a more detailed coverage than has been available until now. Henry Faul died before the manuscript was completed. Anyone who knew Henry will recognize his style, his perception and his scholarship - this book is a fitting memorial.

Keith Bell is a Professor in the Department of Geology, Carleton University, Ottawa.

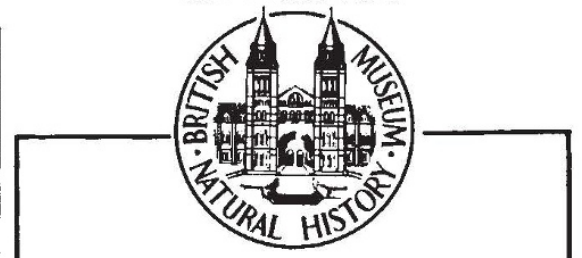

Bats: a natural history.

By John E. Hill \& James D. Smith. This detailed and authoritative study discusses all aspects of bat biology and behaviour. Its scope will make it of value to naturalists, conservationists and zoologists alike. May 31st 248pp copious line and zoologists alike. May 31st. 248pp. copious

Milkweed butterflies. By

R. I. Vane-Wright and P. R. Ackery.

A much needed definitive work on the world's Danainae butterflies, providing an acceptable taxonomic framework in which to place the wealth of data available on this group. 1984, 448pp, with $12 \mathrm{pp}$ colour and $73 \mathrm{pp}$ black and white plates. () 565008935 . Hardback.

If ordered before August 31st, $£ 45.00$.

Afterwards $£ 50.00$.

Ferns of Jamaica. By G. R. Proctor.

An important taxonomic record and description of the 579 species and 30 varieties of ferns occurring in Jamaica. All genera are illustrated and full in Jamica. All generarenter distributional data is given. Seprember 1984. $600 \mathrm{pp}$ approx. 135 line drawings and 22 maps.

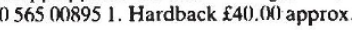

The generic names of moths of the world, Vol. V. Pyraloidea.

By I. W. B. Nye \& D. S. Fletcher.

This series aims to provide a complete list of generic names, their type species. designation and appropriate references for each family treated. thereby rectifying present confusion and giving the basis for a stable nomenclature. May 1984, 200pp approx. 0565008803 . Hardback $£ 25.00$

Catalogue of the ocean bottom deposits collection in the B.M. (N.H.) Part 2. Indian and Pacific oceans. By H. A. Buckley et al.

May 1984, 5 microfiche with booklet and maps. 0565008633 . $\$ 16.00$.

Catalogue of the rock collections in the B.M. (N.H.), 2nd edition. May 1984, 154pp. 0565 (X)1875 7. Paperback f17.50.

Catalogue of the type and figured specimens of Trilobites in the B.M. (N.H.). By S. F. Morris \&

R. A. Fortey.

May 1984, 176pp. $056500882 \mathrm{X}$

Paperback $£ 20 .(0)$ approx.

Catalogue of primates in the B.M. (N.H.) \& elsewhere in the British Isles Part 3. Family Cercopithecidae subfamily Colobinae. By P. H. Napier. 1984. 056500849 3. Hardback f30.00 approx.

An introduction to the

Ichneumonidae of Australia.

By I. D. Gauld.

May 1984, 420pp approx. 58() figs. and 3 maps. 056500896 X. Papcrback $£ 37.50$.

Catalogue of the Natural History Drawings commissioned by Joseph

Banks on the Endeavour voyage 1768-1771 held in the B.M.

(N.H.)

Part 1. Botany: Australia.

By J. A. Diment et al.

1984. 056500937 (). Paperback 530.(0).

Publications Sales. British Museum (Natural History). Cromwell Road, London SW7 5BD. 